(c) American Dairy Science Association, 2006.

\title{
Comparison of Two Strategies for Systemic Antibiotic Treatment of Dairy Cows with Retained Fetal Membranes: Preventive vs. Selective Treatment
}

\author{
M. Drillich, ${ }^{1}$ U. Reichert, M. Mahlstedt, and W. Heuwieser \\ Clinic for Reproduction, Faculty of Veterinary Medicine, Free University of Berlin, Königsweg 65, D-14163 Berlin, Germany
}

\begin{abstract}
The objective of this study was to evaluate the efficacy of a blanket systemic preventive treatment (PT) of cows having retained fetal membranes (RFM) with $1 \mathrm{mg} /$ $\mathrm{kg}$ of ceftiofur administered the first day after calving regardless of their body temperature. This strategy was compared with a selective treatment (ST) strategy in which only cows having RFM and a rectal temperature $\geq 39.5^{\circ} \mathrm{C}$ within $10 \mathrm{~d}$ postpartum received ceftiofur. Cows that retained their fetal membranes for at least $24 \mathrm{~h}$ after calving were allocated to 2 groups. Rectal temperature was measured daily for $10 \mathrm{~d}$ postpartum. Sixty PT cows having RFM received a daily ceftiofur (1 $\mathrm{mg} / \mathrm{kg}$ of body weight) treatment, administered subcutaneously during the first $3 \mathrm{~d}$ after diagnosis of RFM. If rectal temperature was $\geq 39.5^{\circ} \mathrm{C}$ after 3 daily treatments, cows received ceftiofur for 2 more days. Therapy in 53 ST cows was based on selective administration of ceftiofur to cows having fever during the first $10 \mathrm{~d}$ postpartum. Treatment was conducted for 3 to 5 consecutive days as described for PT cows, beginning on the first day of fever. In both groups, manual removal of the placenta was not attempted and antibiotic drugs were not administered into the uterus. For every cow having RFM enrolled in PT or ST, 1 cow without RFM that had calved on the same day was enrolled in a healthy control group $(\mathrm{n}=113)$. All cows received two 25-mg doses of $\mathrm{PGF}_{2 \alpha}: 1$ dose between 18 and $24 \mathrm{~d}$ and 1 dose between 32 and 38 d postpartum. The PT did not reduce the proportion of cows experiencing fever during $10 \mathrm{~d}$ postpartum compared with ST cows (71.7 vs. $69.8 \%$ ). Results were compared using logistic regression models and survival analyses. The artificial insemination submission rate between 42 and $62 \mathrm{~d}$ postpartum was greater in PT (41.2 vs. 20.8 vs. $24.5 \%$ ), but total conception rate was less in ST and control cows, respectively ( 25.0 vs. 38.9 vs. $36.2 \%$ ). In this trial, a preventive systemic antibiotic treatment of all cows
\end{abstract}

Received August 15, 2005.

Accepted December 8, 2005.

${ }^{1}$ Corresponding author: author@bestandsbetreuung.de having RFM was not superior to a selective antibiotic treatment of cows only in case of fever.

Key words: retained fetal membrane, ceftiofur, reproductive performance, dairy cow

\section{INTRODUCTION}

Retained fetal membranes (RFM) in dairy cows is defined as the failure to expel the fetal membranes by 12 to $24 \mathrm{~h}$ after calving (Fourichon et al., 2000). Average incidence of RFM ranges from 3 to $12 \%$ of normal calvings (Paisley et al., 1986; Esslemont and Kossaibati, 1996; Eiler, 1997). A meta-analysis of publications on reproductive disorders by Fourichon et al. (2000) revealed a negative impact of RFM on reproductive performance during the current lactation. Frequent occurrence of metritis after RFM was identified as the main reason for reduced fertility of cows having RFM (Laven and Peters, 1996; Gröhn and Rajala-Schultz, 2000). Postpartum metritis can be characterized by pyrexia up to $10 \mathrm{~d}$ postpartum with a fetid, purulent vulvar discharge, often associated with delayed involution of the uterus (Sheldon and Dobson, 2004). Between 35 and 95\% of cows with RFM have an elevated temperature (Stevens et al. 1995; Overton et al., 2003; Drillich et al., 2003, 2006).

In Europe (Laven, 1995), and to some extent in the United States and Canada, a common treatment of RFM in veterinary practice is based on the manual removal of the placenta and local antibiotic therapy (Peters and Laven, 1996). Convincing evidence, however, exists for a systemic antibiotic treatment with ceftiofur as an efficacious treatment of RFM (Drillich et al., 2003; Risco and Hernandez, 2003) without manual removal of RFM (Bolinder et al., 1988) or intrauterine administration of antibiotics (Drillich et al., 2006). Elevated body temperature was a criterion for the administration of systemic antibiotics in numerous studies on metritis (Smith et al., 1998; Drillich et al., 2001; Chenault et al., 2004) or RFM (Stevens et al., 1995; Drillich et al., 2003, 2005, 2006; Overton et al., 2003; Risco and Hernandez, 2003). Because of the potentially lifethreatening character of acute metritis (Eiler, 1997), it 
is a questionable practice to leave feverish RFM cows untreated. Efficacy of a treatment of acute metritis, often associated with RFM, with a systemic administration of penicillin, oxytetracycline, or ceftiofur has been demonstrated (Smith et al., 1998; Drillich et al., 2001; Chenault et al., 2004). A significant decrease in rectal temperature after treatment with $1 \mathrm{mg} / \mathrm{kg}$ of ceftiofur has been demonstrated compared with untreated postpartum feverish cows (Zhou et al., 2001). Risco and Hernandez (2003) demonstrated that the administration of $2.2 \mathrm{mg} / \mathrm{kg}$ of ceftiofur to cows having RFM for 5 $\mathrm{d}$ after calving reduced the risk for metritis. Subcutaneous administration of $1 \mathrm{mg}$ of ceftiofur/ $\mathrm{kg}$ of BW produced concentrations of ceftiofur derivates in uterine tissues (Okker et al., 2002) that exceeded the reported minimum inhibitory concentrations for intrauterine Escherichia coli, Fusobacterium necrophorum, and Arcanobacterium pyogenes (Sheldon et al., 2004a).

The objective of our study was to test whether a preventive treatment of cows having RFM with ceftiofur beginning on 11 after calving, regardless of an elevated body temperature, would reduce occurrence of fever and improve reproductive performance of cows compared with a selective treatment of RFM cows with ceftiofur only in the case of fever. Furthermore, the hypothesis was tested that a preventive treatment would result in reproductive performance that does not differ from that of control cows without RFM.

\section{MATERIALS AND METHODS}

The study was conducted between June 2002 and November 2003 on a commercial dairy farm in Germany. The participating farmer and the local veterinarian were informed about all relevant characteristics of the study and agreed with the study design. A total of 1,150 cows were housed in freestall barns with sand bedding. One week before expected calving, cows were moved into a freestall barn with straw bedding. Herd average milk yield was $10,700 \mathrm{~kg}$ per lactation $(4.0 \%$ fat, 3.6\% protein). Cows were fed a TMR consisting of corn silage, grass silage, hay, and concentrates. The voluntary waiting period (VWP) was set at $42 \mathrm{~d}$ postpartum. Cows observed in estrus were inseminated artificially. Pregnancy diagnosis was performed by ultrasound between 32 and $38 \mathrm{~d}$ after AI. Cows not inseminated by $83 \mathrm{~d}$ postpartum or identified as not pregnant were treated with the Ovsynch protocol (Pursley et al., 1997).

Cows that retained their fetal membranes for at least $24 \mathrm{~h}$ after calving were included in the study. Cows having a caesarean section and those identified to be culled (not to be inseminated) after calving were not enrolled. All cows that received antiinflammatory or systemic antibiotic drugs during $10 \mathrm{~d}$ postpartum for purposes unrelated to the study (e.g., acute mastitis) were excluded retrospectively from the trial. During the first $10 \mathrm{~d}$ postpartum, rectal body temperature was measured daily in all RFM cows. A body temperature $\geq 39.5^{\circ} \mathrm{C}$ was regarded as a fever.

Cows with RFM were assigned to receive 1 of 2 treatments according to their ear tag identification. Cows with uneven ear tag numbers were enrolled in the preventive treatment (PT) group, and cows with even ear tag numbers were enrolled in the selective treatment (ST) group. All PT cows received the systemic antibiotic treatment of $1 \mathrm{mg} / \mathrm{kg}$ of ceftiofur (Excenel RTU, Pfizer Animal Health, Karlsruhe, Germany), administered subcutaneously on the day of enrollment (d 1). The treatment was repeated once daily for 3 consecutive days. Cows with fever on d 4 received $1 \mathrm{mg} / \mathrm{kg}$ of ceftiofur for an additional $2 \mathrm{~d}$. In the case of fever after $5 \mathrm{~d}$ of treatment with ceftiofur, cows received an escape therapy (i.e., a different systemic antibiotic chosen by the local veterinarian). The ST cows were administered ceftiofur only when feverish during $10 \mathrm{~d}$ postpartum. Treatment was conducted for 3 to 5 consecutive days as described for PT cows, beginning on the first day of fever. In both groups of treated cows, fetal membranes were not removed manually and antibiotics were not administered in the uterus. Considering the potentially life-threatening character of toxic puerperal metritis following RFM (Eiler, 1997), an untreated control group was not included. After enrollment of a cow into PT or ST, the next cow to calve without RFM was enrolled into a healthy control group.

In Europe, ceftiofur is approved for acute postpartum metritis during the first $10 \mathrm{~d}$ postpartum at a dosage of $1 \mathrm{mg} / \mathrm{kg}$ of BW. However, in the United States, ceftiofur is approved for a dosage of $2.2 \mathrm{mg} / \mathrm{kg}$ of BW. Administration of $1 \mathrm{mg} / \mathrm{kg}$ of ceftiofur in RFM cows would be considered an extra-label use in the United States.

All cows were treated with $25 \mathrm{mg}$ of $\mathrm{PGF}_{2 \alpha}$ intramuscularly (Dinolytic, Pfizer Animal Health) between 18 and $24 \mathrm{~d}$ postpartum and again between 32 and $38 \mathrm{~d}$ postpartum to support the involution of the uterus. This was a standard operating procedure established on this dairy farm for many years.

All treatments were documented on case report forms, which remained on farm to ensure that all cows received the correct treatments each day. At the end of the study, case report forms were checked for compliance and plausibility of the data. Cows with incomplete treatments or other deviations from the treatment protocol were retrospectively deleted from the study. Cows were monitored daily and data were documented for a period of $200 \mathrm{~d}$ postpartum. Reproductive performance was characterized by AI submission rate during 42 to 
$62 \mathrm{~d}$ postpartum (number of cows inseminated between 42 and $62 \mathrm{~d}$ divided by number of cows exceeding the $\mathrm{VWP} \times 100$ ), AI submission rate between 63 and $83 \mathrm{~d}$ (number of cows inseminated between 63 and $83 \mathrm{~d}$ divided by number of cows exceeding the VWP, but not inseminated $\times 100$ ), days to first AI, days to pregnancy, first AI conception rate, total conception rate (number of cows pregnant divided by total number of inseminations $\times 100$ ), cows pregnant, and cows culled. Cows not pregnant by 200 DIM were regarded as open, even if they remained in the herd and conceived later in lactation.

\section{Statistical Analyses}

Data were analyzed using SPSS for Windows (Version 12.0, SPSS Inc., Munich, Germany). Proportions of cows with fever at the day of enrollment, during 10 $\mathrm{d}$ postpartum, and after 3- and 5-d treatments, respectively, were compared between treatments (PT vs. ST) by using $\chi^{2}$ analyses. Binary logistic regression models were calculated for the risks of the first insemination within $21 \mathrm{~d}$ after the end of VWP (AI submission rate 42 to $62 \mathrm{~d}$ ), conception after first AI (first AI conception rate), and conception after all inseminations (total conception rate) as outcome variables. Survival analyses for days to first AI, days to pregnancy, and days to culling were performed by using Cox regression, censoring cows that were not inseminated, not pregnant, and not culled, respectively. For logistic regression models as well as for survival analyses, treatment (PT, ST, and control) and parity (multiparous vs. primiparous) were included as covariates. Adjusted odds ratios, hazard ratios, confidence intervals, and $P$-values are reported. To test the hypotheses in this study, PT was chosen as the reference group for all logistic regression models and survival analyses. For logistic regression as well as for survival analyses, the confidence interval was set at $95 \%$ and level of significance at $\alpha=0.05$.

\section{RESULTS}

Incidence of RFM during the study period was $8.7 \%$. One hundred thirty-five RFM cows were enrolled in the study. Of those, 9 cows with clinical ketosis (6 PT and 3 ST cows) were removed because of treatments with dexamethasone; 9 cows (6 PT and 3 ST cows) because they received ceftiofur not in accordance with the treatment protocol; 3 cows ( 2 PT and 1 ST cow) because they had a fever and did not receive ceftiofur; and 1 PT cow was removed because of a systemic antibiotic treatment after surgery for displaced abomasum. After exclusion of these cows, 113 RFM cows (60 PT and 53 ST) and 113 control cows without RFM were eligible for evalua- tion. The proportion of primiparous cows per PT, ST, and control groups was $25.0,26.4$, and $32.7 \%$, respectively.

Clinical traits in PT and ST cows during the first 10 d postpartum are presented in Table 1. Proportion of cows having a fever during $10 \mathrm{~d}$ postpartum was 71.7 and $69.8 \%$ in PT and ST, respectively. Proportion of cows with a fever after $3 \mathrm{~d}$ of treatment was $38.3 \%$ in PT and $43.2 \%$ in ST. An escape therapy because of fever after 5 daily treatments was administered in 2 cases per group. None of the outcomes differed between treatments in Table 1. Seasonal effects (winter, spring, summer, and autumn) on the occurrence of fever were tested, but did not differ among seasons.

Descriptive reproductive performance results are given in Table 2. Results of logistic regression models are shown in Table 3 . A reduced $(P<0.05)$ risk of insemination by $21 \mathrm{~d}$ after the end of the VWP was evident for ST and control cows compared with PT cows. The AI submission rates increased in the subsequent service interval (AI submission rate from 63 to $83 \mathrm{~d}$ ), but did not differ between treatments. First AI conception rate was not affected by group, whereas total conception rate was greater $(P<0.05)$ in ST and controls, respectively, compared with PT. Survival analyses revealed no significant effects of treatment on days to first AI, days to pregnancy, and days to culling, respectively (Table 4). Primiparous cows were inseminated later and conceived later than multiparous cows $(P<0.05)$.

Possible interactions of treatment and the duration of fever on reproductive performance measures were tested, but were not significant.

\section{DISCUSSION}

This study was conducted to test the hypothesis that a preventive treatment of all RFM cows with ceftiofur $(1 \mathrm{mg} / \mathrm{kg}$ of BW) at $\mathrm{d} 1$ after calving would reduce occurrence of fever and improve reproductive performance compared with selective treatment of cows once fever was detected during the first $10 \mathrm{~d}$ postpartum. Furthermore, the hypothesis was tested that a preventive treatment would produce reproductive performance comparable with control cows without RFM.

Retained fetal membranes is often associated with postpartum metritis (Correa et al., 1993; Eiler, 1997; Drillich et al., 2003). Postpartum metritis is characterized by an elevated body temperature, fetid purulent vulvar discharge, often associated with delayed uterine involution (Sheldon and Dobson, 2004). Although presence of a fever alone is not sufficient for the diagnosis of metritis, elevated rectal temperature was a criterion for administration of systemic antibiotics in numerous studies involving acute, toxic metritis and RFM (Ste- 
Table 1. Clinical traits identified during first $10 \mathrm{~d}$ postpartum in cows having retained fetal membranes (RFM)

\begin{tabular}{|c|c|c|}
\hline \multirow[b]{2}{*}{ Trait } & \multicolumn{2}{|c|}{ Treatment ${ }^{1}$} \\
\hline & PT & ST \\
\hline No. of cows & 60 & 53 \\
\hline Cows with fever at $1 \mathrm{~d}$ postpartum, ${ }^{1} \%$ (n) & $18.3(11 / 60)$ & $15.1(8 / 53)$ \\
\hline Cows with fever within $10 \mathrm{~d}$ postpartum, ${ }^{1} \%$ (n) & $71.7(43 / 60)$ & $69.8(37 / 53)$ \\
\hline Median first day of fever (interquartile range) & $3.0(1.0-4.0)$ & $2.0(2.0-4.0)$ \\
\hline Cows with fever after 3 treatments, ${ }^{2} \%$ (n) & $38.3(23 / 60)$ & $43.2(16 / 37)$ \\
\hline Cows with fever after 5 treatments, ${ }^{2} \%$ (n) & $3.3(2 / 60)$ & $5.4(2 / 37)$ \\
\hline Median day of RFM shedding (interquartile range) & $3.0(2.0-4.0)$ & $3.0(3.0-4.0)$ \\
\hline Cows culled within $10 \mathrm{~d}$ postpartum $1 \%$ (n) & $5.0(3 / 60)$ & $3.8(2 / 53)$ \\
\hline Total number of treatments ${ }^{2,3}$ & 222 & 145 \\
\hline Median total treatments per treated $\mathrm{cow}^{2,3}$ (interquartile range) & $3.0(3.0-4.0)$ & $3.0(3.0-5.0)$ \\
\hline
\end{tabular}

${ }^{1}$ Treatments were initiated at $1 \mathrm{~d}$ postpartum with $1 \mathrm{mg}$ of ceftiofur/kg of BW for 3 or $5 \mathrm{~d}$, irrespective of body temperature (preventive treatment, PT). For cows having RFM, treatment with $1 \mathrm{mg}$ of ceftiofur/ $\mathrm{kg}$ of BW was administered 3 or $5 \mathrm{~d}$ only when fever exceeded $39.5^{\circ} \mathrm{C}$ (selective treatment, ST).

${ }^{2}$ Subcutaneous administration of $1 \mathrm{mg}$ of ceftiofur $/ \mathrm{kg}$ of BW once daily for 3 consecutive days. When fever was present after $3 \mathrm{~d}$, treatment was continued for 2 more days.

${ }^{3} \mathrm{An}$ escape therapy was administered to cows having fever after 5 daily treatments with ceftiofur consisted of 3 other antibiotic treatments.

vens et al., 1995; Dinsmore et al., 1996; Smith et al., 1998; Kristula et al., 2001; Zhou et al., 2001; Drillich et al., 2001, 2003; Risco and Hernandez, 2003; Chenault et al., 2004). Quality of discharge and the size of the early postpartum uterus are difficult to quantify objectively. Therefore, a rectal temperature $\geq 39.5^{\circ} \mathrm{C}$, not the diagnosis of acute metritis, was chosen as the criterion to evaluate clinical efficacy of treatment protocols. Body temperature that can be regarded as fever varies from $39.2^{\circ} \mathrm{C}$ (Smith et al., 1998) to $39.5^{\circ} \mathrm{C}$ (Stevens et al., 1995; Drillich et al., 2001, 2003; Risco and Hernandez, 2003; Chenault et al., 2004) and $39.7^{\circ} \mathrm{C}$ (Dinsmore et al., 1996; Overton et al., 2003; Sheldon et al., 2004b).

Clinical traits tested (e.g., proportion of cows having a fever within $10 \mathrm{~d}$ postpartum, proportion of feverish cows after 3 or 5 daily treatments, and time of shedding of the fetal membranes) were not affected by PT compared with ST. Prevalence of fever at enrollment and during $10 \mathrm{~d}$ postpartum was consistent with data from a field trial conducted on 5 dairy farms including 501 RFM cows (Drillich et al., 2006). In that study, we found the proportion of feverish cows at $\mathrm{d} 1$ to be between 24 and $32 \%$. In 4 different treatments, the proportions increased up to between 71.5 and $85.5 \%$ by $10 \mathrm{~d}$ postpartum. In a retrospective study (Kristula et al., 2001), the prevalence of fever $\left(>39.2^{\circ} \mathrm{C}\right)$ in $\mathrm{RFM}$ cows was $93 \%$. The average first day of fever was $\mathrm{d} 3$ postpartum. In contrast, in a study with $70 \mathrm{RFM}$ cows on one farm (Drillich et al., 2003), we found that $77.1 \%$ of the cows had a fever at d 1 after calving. Stevens et al. (1995)

Table 2. Descriptive statistics of reproductive performance during 200 DIM for cows having retained fetal membranes (RFM)

\begin{tabular}{llll}
\hline & & \multicolumn{2}{c}{ Treatment $^{1}$} \\
\cline { 2 - 4 } Trait & PT & ST & Control \\
\hline No. of cows & 60 & 53 & 113 \\
Cows inseminated \% $\left(95 \% \mathrm{CI}^{2}\right)$ & $85.0(75.1-93.2)$ & $79.3(67.4-89.2)$ & $88.5(82.2-93.9)$ \\
AI submission rate 42-62 d, \% (95\% CI) & $41.2(27.3-53.1)$ & $20.8(8.3-31.3)$ & $24.5(15.7-32.4)$ \\
AI submission rate 63-83 d, \% (95\% CI) & $63.3(44.4-78.9)$ & $70.0(62.5-81.3)$ & $60.0(48.2-70.4)$ \\
Median days to first AI (interquartile range) & $66.0(60.0-78.0)$ & $42.9(26.7-56.6)$ & $46.5(62.3-89.5)$ \\
First AI conception rate, \% (95\% CI) & $29.4(15.9-40.9)$ & $36.8(26.6-46.0)$ & $36.2(29.9-49.1)$ \\
Total conception rate, \% (95\% CI) & $25.0(17.6-31.7)$ & $91.0(70.0-132.0)$ & $92.0(69.3-121.3)$ \\
Median days to pregnancy (interquartile range) & $83.5(67.3-138.5)$ & $66.0(52.3-77.8)$ & $74.3(65.8-81.9)$ \\
Cows pregnant, \% (95\% CI) & $60.0(46.8-71.6)$ & $66.0(15.0-114.0)$ & $30.0(9.3-142.5)$ \\
Median days to culling (interquartile range) & $38.0(12.5-123.3)$ & $28.3(15.2-39.5)$ & $17.7(10.2-24.3)$ \\
Cows culled, \% (95\% CI) & $23.3(11.8-33.2)$ & \\
\hline
\end{tabular}

\footnotetext{
${ }^{1}$ Treatment was initiated at $1 \mathrm{~d}$ postpartum with $1 \mathrm{mg}$ of ceftiofur/kg of BW for 3 or $5 \mathrm{~d}$, irrespective of body temperature (preventive treatment, PT). For cows having RFM, treatment with $1 \mathrm{mg}$ of ceftiofur $/ \mathrm{kg}$ of BW was administered 3 or $5 \mathrm{~d}$ only when fever exceeded $39.5^{\circ} \mathrm{C}$ (selective treatment, ST). Cows without RFM were controls.

${ }^{2} \mathrm{CI}=$ Confidence interval.
} 
Table 3. Risks of first AI within $21 \mathrm{~d}$ after the end of the voluntary waiting period (VWP, AI submission rate 42 to $62 \mathrm{~d}$ ), conception after first AI, and conception after all inseminations (total conception rate)

\begin{tabular}{|c|c|c|c|c|c|c|c|c|c|c|}
\hline \multirow[b]{2}{*}{ Factor } & \multirow[b]{2}{*}{$\mathrm{df}$} & \multicolumn{3}{|c|}{$\begin{array}{l}\text { AI submission rate } \\
42 \text { to } 62 \mathrm{~d}^{1}\end{array}$} & \multicolumn{3}{|c|}{ Conception after first $\mathrm{AI}^{2}$} & \multicolumn{3}{|c|}{ Total conception ${ }^{3}$} \\
\hline & & $\mathrm{OR}^{4}$ & $95 \% \mathrm{CI}^{5}$ & $P$ & OR & $95 \% \mathrm{CI}$ & $P$ & OR & $95 \% \mathrm{CI}$ & $P$ \\
\hline $\begin{array}{l}\text { Treatment }^{6} \\
\text { PT }\end{array}$ & 2 & & Reference & 0.046 & & Reference & 0.27 & & Reference & 0.04 \\
\hline ST & 1 & 0.37 & $0.15-0.91$ & 0.03 & 1.89 & $0.80-4.49$ & 0.15 & 1.77 & $1.01-3.12$ & 0.046 \\
\hline Control & 1 & 0.45 & $0.22-0.94$ & 0.03 & 1.71 & $0.82-3.56$ & 0.15 & 1.76 & $1.10-2.80$ & 0.02 \\
\hline Parity $^{7}$ & 1 & 1.10 & $0.54-2.25$ & 0.79 & 0.59 & $0.29-1.19$ & 0.14 & 0.80 & $0.51-1.23$ & 0.31 \\
\hline Constant & 1 & 0.69 & & 0.20 & & & 0.01 & 0.35 & & 0.00 \\
\hline
\end{tabular}

${ }^{1}$ No. of cows inseminated during $21 \mathrm{~d}$ after the end of VWP.

${ }^{2}$ No. of cows that conceived after first AI.

${ }^{3}$ No. of total pregnancies after all inseminations.

${ }^{4} \mathrm{OR}=$ Odds ratio.

${ }^{5} \mathrm{CI}=$ Confidence interval.

${ }^{6} \mathrm{PT}=$ Cows having retained fetal membranes (RFM) started treatment at $1 \mathrm{~d}$ postpartum with $1 \mathrm{mg}$ of ceftiofur/kg of BW during 3 to $5 \mathrm{~d}$, irrespective of body temperature; ST $=$ RFM cows started treatment with $1 \mathrm{mg}$ of ceftiofur/ $\mathrm{kg}$ of BW during 3 to $5 \mathrm{~d}$ only when body temperature was $\geq 39.5^{\circ} \mathrm{C}$; Control = cows without RFM.

${ }^{7}$ Multiparous vs. primiparous cows.

reported that $14 \%$ of RFM cows treated initially with oxytetracycline had rectal temperature that exceeded $39.5^{\circ} \mathrm{C}$ during the postpartum period, whereas $26 \%$ of untreated cows had a fever. Unfortunately, incidence of fever in the control cows was not monitored. Periparturient hygienic conditions might help to explain the differences in these studies.

Surprisingly, in the current study, the proportion of feverish cows was not reduced by preventive antibiotic treatment. This is in contrast to findings by Risco and Hernandez (2003) who described that $13 \%$ of RFM cows developed metritis (fever and fetid discharge) after a preventive treatment with ceftiofur compared with $42 \%$ of untreated cows. One explanation for the high proportion of PT cows having a fever might be the dosage of $1 \mathrm{mg}$ of ceftiofur/kg of BW used; Risco and Hernandez
(2003) administered $2.2 \mathrm{mg} / \mathrm{kg}$ of BW. Chenault et al. (2004) found the administration of $2.2 \mathrm{mg} / \mathrm{kg}$ to be more efficacious for the treatment of acute metritis than a dosage of $1.1 \mathrm{mg} / \mathrm{kg}$. In another study with cows having fever $\left(\geq 39.5^{\circ} \mathrm{C}\right)$ after calving, the proportion of cows with fever decreased by $10 \mathrm{~d}$ after administration of 1 $\mathrm{mg}$ of ceftiofur/kg of BW compared with untreated cows. Cows with additional vaginal discharge at enrollment benefited more from antibiotic treatment than did cows without discharge (Zhou et al., 2001).

It is unknown whether fever in PT cows was caused by bacterial resistance to ceftiofur, by toxins released from bacteria, or from necrotic tissue in the uterine lumen. Sheldon et al. (2004b) found a significant correlation between the presence of pathogenic bacteria (A. pyogenes, E. coli, $F$. necrophorum, Prevotella spp.) in

Table 4. Results of the survival analyses (Cox regression) for the days to first AI, days to pregnancy, and days to culling during 200 DIM

\begin{tabular}{|c|c|c|c|c|c|c|c|c|c|c|}
\hline \multirow[b]{2}{*}{ Factor } & \multirow[b]{2}{*}{$\mathrm{df}$} & \multicolumn{3}{|c|}{ Days to first AI } & \multicolumn{3}{|c|}{ Days to pregnancy } & \multicolumn{3}{|c|}{ Days to culling } \\
\hline & & $\mathrm{HR}^{1}$ & $95 \% \mathrm{CI}^{2}$ & $P$ & $\mathrm{HR}$ & $95 \% \mathrm{CI}$ & $P$ & HR & $95 \% \mathrm{CI}$ & $P$ \\
\hline $\begin{array}{l}\text { Treatment } \\
\text { PT }\end{array}$ & 2 & & Reference & 0.37 & & Refe & 0.15 & & $\operatorname{Re}$ & 0.26 \\
\hline ST & 1 & 0.76 & $0.50-1.14$ & 019 & 1.15 & 0.7 & 057 & 1.17 & 0.5 & 0.67 \\
\hline Control & 1 & 0.95 & $0.67-1.32$ & 0.74 & 1.44 & $0.98-2.14$ & 0.06 & 0.69 & $0.34-1.36$ & 0.28 \\
\hline Parity $^{4}$ & 1 & 0.70 & $0.51-0.97$ & 0.03 & 0.70 & $0.49-1.00$ & 0.049 & 1.77 & $0.99-3.16$ & 0.052 \\
\hline
\end{tabular}

${ }^{1} \mathrm{HR}=$ Hazard ratio.

${ }^{2} \mathrm{CI}=$ Confidence interval.

${ }^{3} \mathrm{PT}=$ Cows having retained fetal membranes (RFM) started treatment at $1 \mathrm{~d}$ postpartum with $1 \mathrm{mg}$ of ceftiofur/kg of BW during 3 to $5 \mathrm{~d}$, irrespective of body temperature; ST = RFM cows started treatment with $1 \mathrm{mg}$ of ceftiofur/ $\mathrm{kg}$ of BW during 3 to $5 \mathrm{~d}$ only when body temperature was $\geq 39.5^{\circ} \mathrm{C}$; Control = cows without RFM.

${ }^{4}$ Multiparous vs. primiparous cows. 
the uterine lumen and a rectal temperature of $39.7^{\circ} \mathrm{C}$ or greater. It has been demonstrated that the administration of $1 \mathrm{mg}$ of ceftiofur $/ \mathrm{kg}$ of BW resulted in concentrations of ceftiofur in uterine tissues that exceed the minimum inhibitory concentrations for bacteria causing uterine infections (Okker et al., 2002). The previous study included only 4 healthy cows.

Decrease in the proportion of ST cows having fever after $3(43.2 \%)$ or $5(5.4 \%)$ daily treatments indicated that a 5-d treatment with ceftiofur is sufficient. By design it was not possible to distinguish between prophylactic and therapeutic effects of the PT. Smith et al. (1998) as well as Chenault et al. (2004) administered systemic antibiotics for 5 consecutive days. In the study by Smith et al. (1998), rectal temperature of cows with toxic puerperal metritis decreased from $\geq 39.7$ to $<39.3^{\circ} \mathrm{C}$ after $3 \mathrm{~d}$ of treatment with $2.2 \mathrm{mg}$ of ceftiofur/ $\mathrm{kg}$ of BW, 22,000 IU of procaine penicillin $\mathrm{G} / \mathrm{kg}$ of BW, or a combination of procaine penicillin $\mathrm{G}$ with intrauterine infusions with $6 \mathrm{~g}$ of oxytetracycline. Chenault et al. (2004) reported a decrease in rectal temperature after $5 \mathrm{~d}$ of treatment with 1.1 and $2.2 \mathrm{mg}$ of ceftiofur/ $\mathrm{kg}$ of BW compared with saline-treated controls.

Retained fetal membranes (often associated with acute metritis) is followed by reduced fertility (Laven and Peters, 1996; Eiler, 1997; Gröhn and RajalaSchultz, 2000). Consequently, it is not sufficient to evaluate the efficacy of a treatment of RFM only by clinical symptoms; reproductive performance in the current lactation must also be considered. A greater AI submission rate in PT cows might indicate that more cows resumed cyclicity sooner after calving or were able to express more pronounced signs of estrus. An epidemiological study by Opsomer et al. (2000) demonstrated that only $51 \%$ of high-yielding dairy cows had regular estrous cycles before $\mathrm{d} 50$ postpartum. Cows with RFM in that study tended to be at risk for delayed resumption of ovarian activity. An increased AI submission rate in the following service interval (AI submission rate 63 to $83 \mathrm{~d}$ ) in all cows supports this hypothesis and might explain that time to first AI was not affected by treatment.

Numerically, risk of conception to first service was least in PT cows. Hillers et al. (1984) found poorer firstservice conception rates for cows inseminated before 50 DIM (32\%) than for cows inseminated after 50 DIM (49 to 57\%). Influence of VWP on conception rates was confirmed by Tenhagen et al. (2004) for cows inseminated according to the Ovsynch protocol at various postpartum stages after 53 to 59 DIM. Therefore, a greater proportion of PT cows inseminated earlier in lactation might have resulted in decreased total conception rates compared with ST and control cows. It remains speculative if a longer VWP might have resulted in similar service and conception rates in all treatments. The number of cows tested in our experiment, however, was insufficient to test this hypothesis.

Differences in conception rates might be caused by irritating effects of antibiotics on the endometrium as described for a local antibiotic treatment (Paisley et al., 1986; Peters and Laven, 1996). In light of numerous large-scale field studies on the treatment of acute metritis and RFM with ceftiofur (Smith et al., 1998; Drillich et al., 2001, 2003; Zhou et al., 2001; Risco and Hernandez, 2003; Chenault et al., 2004), a detrimental effect of a subcutaneous administration of ceftiofur on fertility seems to be very unlikely.

The negative impact of RFM on reproductive performance has been demonstrated (Laven and Peters, 1996; Fourichon et al., 2000; Gröhn and Rajala-Schultz, 2000). An optimal therapy would lead to a similar reproductive performance of affected and unaffected cows or at least mitigate the effect of RFM or fever on reproductive performance. Significantly greater total conception rates in control cows revealed that the PT strategy did not result in reproductive performance similar to cows without RFM. In most prospectively controlled studies on treatment of RFM, the number of cows was limited because of the low prevalence of the condition and limited resources. Group sizes of relevant studies by other authors range from 31 (Risco and Hernandez, 2003) to 53 and 58 cows (Stevens et al., 1995; Overton et al., 2003) and are comparable to the enrollment of the present study. Despite the limited statistical power, these studies provide valuable information about the treatment of RFM in dairy cows. Without a significant positive effect on health or productivity the blanket use of antimicrobials cannot be justified.

\section{CONCLUSIONS}

In this trial, a preventive systemic administration of $1 \mathrm{mg}$ of ceftiofur/kg of BW to each cow with RFM at d 1 after calving, regardless of rectal temperature, was not superior to a strategy based on a selective antibiotic treatment of RFM cows only in case of fever during 10 $\mathrm{d}$ postpartum. The PT failed to reduce occurrence of fever over the first $10 \mathrm{~d}$ postpartum. Whereas AI submission rate within 42 to $62 \mathrm{~d}$ postpartum was greater for cows that received the PT, total conception rate was less in this treatment than when cows were treated only in case of fever (ST). Greater total conception rates in control cows revealed that the preventive antibiotic treatment did not result in reproductive performance similar to cows without RFM. 


\section{ACKNOWLEDGMENTS}

The authors gratefully acknowledge the support of the study by Pfizer Animal Health USA, Pfizer Animal Health Germany, and the cooperation of the farm staff.

\section{REFERENCES}

Bolinder, A., B. Seguin, H. Kindahl, D. Bouley, and D. Otterby. 1988. Retained fetal membranes in cows: Manual removal versus nonremoval and its effect on reproductive performance. Theriogenology $30: 45-56$.

Chenault, J. R., J. F. McAllister, S. T. Chester, K. J. Dame, F. M. Kausche, and E. J. Robb. 2004. Efficacy of ceftiofur hydrochloride sterile suspension administered parenterally for the treatment of acute postpartum metritis in dairy cows. J. Am. Vet. Med. Assoc. 224:1634-1639.

Correa, M. T., H. Erb, and J. Scarlett. 1993. Path analysis for seven postpartum disorders of Holstein cows. J. Dairy Sci. 76:13051312 .

Dinsmore, R. P., R. D. Stevens, M. B. Cattell, M. D. Salman, and S. F. Sundlof. 1996. Oxytetracycline residues in milk after intrauterine treatment of cows with retained fetal membranes. J. Am. Vet. Med. Assoc. 209:1753-1755.

Drillich, M., O. Beetz, A. Pfützner, M. Sabin, H.-J. Sabin, P. Kutzer, H. Nattermann, and W. Heuwieser. 2001. Evaluation of a systemic antibiotic treatment of toxic puerperal metritis in dairy cows. J. Dairy Sci. 84:2010-2017.

Drillich, M., M. Mahlstedt, U. Reichert, B. A. Tenhagen, and W. Heuwieser. 2006. Strategies to improve the therapy of retained fetal membranes in dairy cows. J. Dairy Sci. 89:627-635.

Drillich, M., A. Pfützner, H.-J. Sabin, M. Sabin, and W. Heuwieser. 2003. Comparison of two protocols for the treatment of retained fetal membranes in dairy cattle. Theriogenology 59:951-960.

Drillich, M., A. Schröder, B. A. Tenhagen, and W. Heuwieser. 2005. Efficacy of a treatment of retained placenta in dairy cows with prostaglandin $\mathrm{F}_{2 \alpha}$ in addition to a local antibiotic treatment. Dtsch. Tierarztl. Wochenschr. 112:174-179.

Eiler, H. 1997. Retained placenta. Pages 340-348 in Current Therapy in Large Animal Theriogenology. R. S. Youngquist, ed. W. B. Saunders Company, Philadelphia, PA.

Esslemont, R. J., and M. A. Kossaibati. 1996. Incidence of production diseases and other health problems in a group of dairy herds in England. Vet. Rec. 139:486-490.

Fourichon, C., H. Seegers, and X. Malher. 2000. Effect of disease on reproduction in the dairy cow: A meta-analysis. Theriogenology 53:1729-1759.

Gröhn, Y. T., and P. J. Rajala-Schultz. 2000. Epidemiology of reproductive performance in dairy cows. Anim. Reprod. Sci. 6061:605-614.

Hillers, J. K., P. L. Senger, R. L. Darlington, and W. N. Fleming. 1984. Effects of production, season, age of cow, days dry, and days in milk on conception to first service in large commercial dairy herds. J. Dairy Sci. 67:861-867.

Kristula, M., B. Smith, and A. Simeone. 2001. The use of daily postpartum rectal temperatures to select dairy cows for treatment with systemic antibiotics. Bovine Pract. 35:117-124.
Laven, R. A. 1995. The treatment of retained placenta. A survey of practitioners. Cattle Pract. 3:267-279.

Laven, R. A., and A. R. Peters. 1996. Bovine retained placenta: Aetiology, pathogenesis and economic loss. Vet. Rec. 139:465-471.

Okker, H., E. J. Schmitt, P. L. A. M. Vos, P. Scherpenisse, A. A. Bergwerff, and F. H. Jonker. 2002. Pharmacokinetics of ceftiofur in plasma and uterine secretions and tissues after subcutaneous postpartum administration in lactating dairy cows. J. Vet. Pharmacol. Therap. 25:33-38.

Opsomer, G., Y. T. Gröhn, J. Hertl, M. Coryn, H. Deluyker, and A. de Kruif. 2000. Risk factors for postpartum ovarian dysfunction in high producing dairy cows in Belgium: A field study. Theriogenology 53:841-857.

Overton, M. W., W. M. Sischo, and J. P. Reynolds. 2003. Evaluation of effect of estradiol cypionate administered prophylactically to postparturient dairy cows at high risk for metritis. J. Am. Vet. Med. Assoc. 223:846-851.

Paisley, L. G., W. D. Mickelsen, and P. B. Anderson. 1986. Mechanism and therapy for retained fetal membranes and uterine infections of cows: A review. Theriogenology 25:353-381.

Peters, A. R., and R. A. Laven. 1996. Treatment of bovine retained placenta and its effects. Vet. Rec. 139:535-539.

Pursley, J. R., M. R. Kosorok, and M. C. Wiltbank. 1997. Pregnancy rates per artificial insemination for cows and heifers inseminated at a synchronized ovulation or synchronized estrus. J. Dairy Sci. 80:295-300.

Risco, C. A., and J. Hernandez. 2003. Comparison of ceftiofur hydrochloride and estradiol cypionate for metritis prevention in dairy cows affected with retained fetal membranes. Theriogenology 60:47-58.

Sheldon, I. M., M. Bushnell, J. Montgomery, and A. N. Rycroft. 2004a. Minimum inhibitory concentrations of some anti microbial drugs against bacteria causing uterine infections in cattle. Vet. Rec. 15:383-387.

Sheldon, I. M., and H. Dobson. 2004. Postpartum uterine health in cattle. Anim. Reprod. Sci. 82-83:295-306.

Sheldon, I. M., A. N. Rycroft, and C. Zhou. 2004b. Association between postpartum pyrexia and uterine bacterial infection in dairy cattle. Vet. Rec. 154:289-293.

Smith, B. I., G. A. Donovan, C. Risco, R. Littell, C. Young, L. H. Stanker, and J. Elliott. 1998. Comparison of various antibiotic treatments for cows diagnosed with toxic puerperal metritis. J. Dairy Sci. 81:1555-1562.

Stevens, R. D., R. P. Dinsmore, and M. B. Cattell. 1995. Evaluation of the use of intrauterine infusion of oxytetracycline, subcutaneous injections of fenprostalene, or a combination of both, for the treatment of retained fetal membranes in dairy cows. J. Am. Vet. Med. Assoc. 207:1612-1615.

Tenhagen, B.-A., R. Surholt, M. Wittke, C. Vogel, M. Drillich, and W. Heuwieser. 2004. Use of Ovsynch in dairy herds-Differences between primiparous and multiparous cows. Anim. Reprod. Sci. 81:1-11.

Zhou, C., J. F. Boucher, K. J. Dame, M. Moreira, R. Graham, J. Nantel, S. Zuidhof, L. Arfi, R. Flores, G. Neubauer, and J. Olson. 2001. Multilocation trial of ceftiofur for treatment of postpartum cows with fever. J. Am. Vet. Med. Assoc. 219:805-808. 